\title{
Strategi Komunikasi Pemasaran Sosial Borneo Orangutan Survival Foundation (BOS Foundation) melalui Instagram
}

\author{
Kezea Yemima, Farid Rusdi \\ kezea.915160033@stu.untar.ac.id,farid@fikom.untar.ac.id \\ Fakultas Ilmu Komunikasi Universitas Tarumanagara
}

\begin{abstract}
Habitat of orangutans that continues to shrink in number can result in the extinction of the existence of orangutans. Tropical rain forests are the habitat of many orangutans used as oil palm plantations. However, not only a few people who want to contribute to the conservation of orangutans and their habitat. Borneo Orangutan Survival Foundation, is a non-profit organization that has concern for orangutans and their habitat. This research is a descriptive qualitative research that discusses social marketing communication strategies carried out by the BOS Foundation to attract public awareness through Instagram in orangutan conservation efforts and the improvement of their habitat. The research data were taken from interviews with three speakers related to this research. The data obtained were analyzed with the SOSTAC concept which discussed the situation, objectives, strategies, tactics, actions, and controls related to the discussion. The conclusion of this study is the social marketing communication strategy undertaken by the BOS Foundation through Instagram is to have a standard in uploading content, containing captions that are interesting to read, also pay attention to the engagement that is generated.
\end{abstract}

Keywords: awareness, bos foundation, social marketing

\begin{abstract}
Abstrak
Habitat orangutan yang terus menyusut jumlahnya dapat mengakibatkan kepunahan dari eksistensi orangutan. Hutan hujan tropis merupakan habitat orangutan yang banyak dijadikan perkebunan kelapa sawit. Namun, tidak sedikit masyarakat yang ingin berkontribusi dalam pelestarian orangutan serta habitatnya. Borneo Orangutan Survival Foundation, adalah salah satu organisasi non-profit yang memiliki kepedulian terhadap orangutan dan habitatnya. Penelitian ini merupakan penelitian kualitatif deskriptif yang membahas tentang strategi komunikasi pemasaran sosial yang dilakukan oleh BOS Foundation guna menarik awareness masyarakat melalui Instagram dalam upaya konservasi orangutan serta perbaikan habitatnya. Data hasil penelitian diambil dari wawancara dengan tiga narasumber terkait penelitian ini. Data yang didapat dianalisis dengan konsep SOSTAC yang membahas tentang situasi, tujuan, strategi, taktik, aksi, dan kontrol terkait pembahasan. Kesimpulan dari penelitian ini adalah strategi komunikasi pemasaran sosial yang dilakukan oleh BOS Foundation melalui Instagram ialah dengan memiliki standarisasi dalam mengunggah konten, memuat caption yang menarik untuk dibaca, juga memperhatikan engagement yang dihasilkan.
\end{abstract}

Kata Kunci: Pemasaran Sosial, BOS Foundation, Awareness

\section{Pendahuluan}

Orangutan merupakan satu-satunya anggota keluarga kera besar yang ditemukan di Asia. Habitat orangutan adalah hutan hujan tropis yang luasnya terus menyusut di dunia. Habitat orangutan terancam oleh kegiatan ekspansi perkebunan 
kelapa sawit karena Indonesia dan Malaysia merupakan produsen minyak kelapa sawit terbesar di dunia. Saat ini orangutan hanya dapat ditemukan di Pulau Sumatera dan Borneo (Kalimantan dan teritori Negara Malaysia yaitu Sabah dan Sarawak).

Kasus pembunuhan orangutan di perkebunan komoditas komersial seperti karet dan kelapa sawit sudah banyak terjadi. Selain itu orangutan juga diburu dan diperdagangkan di pasar online. Lemahnya penegakan hukum membuat kejahatankejahatan ini terus berlangsung. Selain itu perkembangbiakkan orangutan terbilang cukup lambat karena orangutan betina baru bisa bereproduksi saat berusia 9-12 tahun dan mengandung selama sembilan bulan. Fenomena-fenomena tersebut mengakibatkan populasi orangutan terus menurun.

Namun tidak sedikit masyarakat yang ingin ikut serta dalam menyelamatkan habitat orangutan. Hal ini ditunjukkan oleh banyak terbentuknya Lembaga Swadaya Masyarakat dalam upaya melakukan konservasi orangutan. Borneo Orangutan Survival Foundation (BOS Foundation) merupakan salah satu organisasi non-profit Indonesia yang didedikasikan untuk konservasi orangutan Borneo dan habitatnya, bekerjasama dengan masyarakat setempat, Kementerian Kehutanan Republik Indonesia dan organisasi mitra internasional.

Non-profit organization merupakan kegiatan yang dilakukan oleh lembagalembaga independen dan sosial yang bersifat sukarela. Mengubah perilaku adalah sebuah proses yang panjang dalam komunikasi pemasaran sosial, namun sangat penting. Untuk menuju perubahan perilaku yang diharapkan berkaitan dengan edukasi. Dalam upaya tersebut, BOS Foundation tentu melakukan kegiatan komunikasi pemasaran sosial supaya menarik kesadaran masyarakat. Untuk melakukan kegiatan komunikasi pemasaran, organisasi perlu upaya agar mendapatkan strategi yang tepat dengan pencapaian yang tepat. Pemasaran digital tidak lagi mempertimbangkan konsep jarak dan waktu untuk menjangkau konsumen karena adanya dukungan teknologi internet yang semakin canggih (Kusniadji, 2017).

Dalam melakukan strategi komunikasi pemasaran sosial, BOS Foundation menggunakan berbagai jenis media sosial. Media sosial sangat ramai digunakan oleh masyarakat luas sebagai sarana informasi dan komunikasi. Selain sebagai sarana berkomunikasi, media sosial juga memberikan manfaat dalam mendapatkan atau memperkenalkan dengan teman-teman baru yang sama-sama menggunakan akun media sosial tersebut. Secara umum fungsi dari media sosial untuk mendukung interaksi sosial bagi para penggunanya (Purnama, 2011).

Media sosial yang dimiliki BOS Foundation yaitu Facebook, Twitter, Instagram, juga terdapat web resmi. Dalam Instagram, BOS Foundation memiliki pengikut sebanyak 58,5k, yang merupakan akun Instagram terkait konservasi orangutan dengan pengikut terbanyak di Indonesia.

\section{Metode Penelitian}

Penulis dalam penelitian ini menggunakan metode penelitian kualitatif dengan jenis pendekatan deskriptif. Muri Yusuf (2014) menjelaskan penelitian kualitatif merupakan suatu strategi inquiry yang menekankan pencarian makna, pengertian, konsep, karakteristik, gejala, simbol, maupun deskripsi tentang suatu fenomena, fokus, dan multimetode. Bogdan dan Taylor (Moleong, 2010) menjelaskan metode penelitian kualitatif merupakan sebuah prosedur penelitian yang menghasilkan data deskriptif berupa kata-kata tertulis maupun lisan dari orang-orang maupun perilaku yang dapat diamati. 
Penelitian deskriptif adalah penelitian yang bermaksud untuk membuat deskripsi mengenai kejadian-kejadian. Dalam arti penelitian deskriptif itu adalah akumulasi data dasar dalam cara deskriptif, semata-mata tidak perlu mencari atau menerangkan yang saling berhubungan, menguji hipotesis, membuat ramalan, atau mendapatkan makna dan implikasi walaupun penelitian bertujuan untuk menemukan hal yang dapat mencakup metode deskriptif (Suryabrata, 2012).

Metode ini terarah untuk mencari arti dan mengerti gejala, peristiwa, juga realita yang terjadi. Terlebih lagi metode-metode ini ingin memahami arti yang terdalam dan hakiki dari suatu gejala, peristiwa, atau realita. Setiap perbuatan atau tindakan orang selalu memiliki arti tersendiri. Tidak ada tindakan yang tidak memiliki maksud dan tujuan. Tindakan yang kelihatannya sama dapat diartikan secara berbeda oleh orang yang berbeda. Arti ini yang hendak dimengerti dan oleh peneliti metode penelitian kualitatif, dan arti yang dimaksud bukannya arti yang umum tetapi arti yang terdalam (J.R. Raco, 2010).

\section{Hasil Temuan dan Diskusi}

Dalam melakukan strategi komunikasi pemasaran sosial oleh BOS Foundation, peneliti menarik beberapa pembahasan yang didasarkan dari hasil wawancara dengan pihak BOS Foundation dengan menggunakan teori SOSTAC. Hasilnya adalah sebagai berikut:

\section{Situation}

Dari berbagai macam media sosial yang ada, tentu terdapat alasan yang mendasari BOS Foundation dalam menggunakan Instagram sebagai media promosi. BOS Foundation menggunakan Instagram karena demografi masyarakat yang menggunakan Instagram berbeda dengan pengguna media sosial lainnya. Pengguna Instagram lebih aktif memberikan komentar dan like terhadap foto atau video yang diunggah. Meskipun hal yang sama dapat dilakukan di Facebook, minat publik terhadap Instagram sangat tinggi dan mulai mengalahkan Facebook terutama di generasi anak muda. Karena itu, BOS Foundation memutuskan untuk membuat akun Instagram.

\section{Objectives}

Tujuan utama BOS Foundation dengan menggunakan Instagram yaitu untuk meningkatkan kesadaran serta kepedulian masyarakat terhadap orangutan dan habitatnya. Untuk itu, BOS Foundation mempromosikan cerita yang ada di artikel lewat Instagram. Selain itu diikuti dengan aktifitas fundraising seperti donasi dan adopsi.

Minat publik terhadap Instagram sangat tinggi sehingga BOS Foundation menggunakan Instagram sebagai salah satu media untuk memberikan informasi terkait orangutan. Dengan demikian kesadaran masyarakat dapat ditingkatkan melalui informasi yang diberikan lewat Instagram. Informasi yang disampaikan tersebut bertujuan untuk menarik perhatian masyarakat agar ikut serta membantu kegiatan konservasi orangutan dengan berdonasi. Donasi yang berikan tentu ditujukan seluruhnya untuk kepentingan konservasi orangutan. Contohnya seperti perbaikan hutan yang menjadi habitat orangutan dirusak akibat kebakaran hutan.

3. Strategy

Untuk mencapai tujuannya BOS Foundation memiliki strategi yang dilaksanakan melalui pemasaran sosial di Instagram. Segala informasi yang ingin disampaikan ke masyarakat dimuat di Instagram melalui fitur-fitur Instagram yang ada. Seperti posting 
foto maupun video pada feeds di Instagram, selain itu terdapat juga Instagram story yang memudahkan para pengikut Instagram BOS Foundation untuk melihat dan berdonasi. Dalam Instagram story, BOS Foundation memuat cara donasi hanya dengan swipe up sehingga memudahkan masyarakat untuk donasi. Hanya dengan sekali klik.

\section{Tactics}

Dalam mempertajam strategi yang telah ditetapkan oleh BOS Foundation, terdapat taktik yang dilakukan. Pertama, dari konten yang diunggah di media sosial Instagram. Konten yang dimiliki BOS Foundation berupa video dan foto. Dalam pembuatan konten tersebut, tentu BOS Foundation memiliki standar dan ketentuan tersendiri. Dalam setiap konten, harus terdapat makna yang dapat direlasikan kepada audiens, agar audiens dapat merasakan hubungan afeksi dari konten yang di unggah. Makna tersebut disampaikan dengan adanya unsur edukasi mengenai orang utan serta habitatnya. Selain itu, unsur edukasi tersebut digabungkan dengan sedikit komedi yang disematkan pada caption agar unggahan terlihat lebih menyenangkan.

Caption yang ditulis BOS Foundation menggunakan bahasa yang mengajak untuk menarik audiens agar membaca cerita yang disajikan. Selain itu, BOS Foundation terkadang menggunakan pertanyaan terbuka agar audiens dapat lebih aktif memberikan komentar pada konten yang diunggah. Sehingga dapat terjadi hubungan 2 arah yang aktif dan masyarakat pun dapat tidak sungkan untuk bertanya atau memberi komentar terkait orangutan.

Bahasa yang digunakan BOS Foundation dalam penulisan caption adalah Bahasa Inggris dan Bahasa Indonesia. Terlihat dari Instagram Insight yang dimiliki BOS Foundation bahwa audiens dari BOS Foundation tidak hanya masyarakat dari Indonesia, melainkan juga dari luar negeri. Sehingga dalam menulis caption harus mencakup seluruh audiens yaitu dengan menggunakan 2 bahasa.

Dalam menentukan waktu pengunggahan konten, BOS Foundation bertumpu pada analisis Instagram insight. Dalam Instagram insight, berisi laporan tentang konten mana yang paling tinggi engagement, serta waktu yang paling sering menunjukan ketika masyarakat membuka Instagram. Hari Kamis merupakan hari dimana engagement tertinggi yang dimiliki oleh BOS Foundation. Sehingga BOS Foundation memilih Hari Kamis untuk mengunggah hal-hal yang berkaitan dengan fundraising atau donasi.

5. Action

Selain penyebaran awareness melalui Instagram, BOS Foundation juga menggunakan Campaigner Awareness, yaitu orang-orang yang cukup dikenal di masyarakat sehingga memudahkan BOS Foundation dalam menyampaikan informasi. Campaigner Awareness tersebut mempromosikan BOS Foundation dengan mengunggah konten-konten maupun memberikan informasi mengenai orangutan. Namun, BOS Foundation tidak sembarangan dalam menentukan Campaigner Awareness karena tidak semua orang yang ingin menjadi Campaigner Awareness tersebut memiliki rasa kepedulian terhadap orangutan. Salah satu Campaigner Awareness yang dimiliki BOS Foundation adalah Davina Veronica. Davina merupakan seorang aktivis lingkungan dan kesejahteraan satwa Indonesia.

\section{Control}

Keberhasilan BOS Foundation dalam melakukan pemasaran sosial lewat Instagram dilihat dari Instagram insight yang dimiliki. Seperti kenaikan jumlah pengikut di Instagram, lalu jumlah penonton yang melihat video atau foto yang diunggah oleh BOS Foundation. Selain itu, melalui komentar-komentar maupun likes 
yang diberikan masyarakat. Setelah menggunakan Instagram selama kurang lebih hampir 3 tahun, peningkatan yang signifikan sudah terlihat. Terlihat dari jumlah pengikut dan engagement yang dilakukan oleh para pengikut akun Instagram BOS Foundation di Instagram.

\section{Kesimpulan}

Dalam penerapan strateginya, BOS Foundation berusaha mencari jalan tengah agar tujuan dapat tersampai pada audience begitupun sebaliknya. Dalam pendistribusian kontennya, BOS Foundation mengerti bahwa yang harus dilakukan adalah menarik kepedulian melalui psikologis audiens. Seperti dengan unggahan yang ada di Instagram, tidak selalu memfokuskan pada kepunahan orang utan, kerusakan hutan yang terus-menerus. Tetapi BOS Foundation menyajikan konten yang menarik seperti kegiatan orang utan yang lucu dan menggemaskan menjadi salah satu konten BOS Foundation agar audiens dapat tertarik untuk melihat unggahan-unggahan mereka.

Selain itu, cara penyampaian informasi yang disajikan lewat caption di Instagram pun menjadi salah satu faktor penting karena mereka tidak hanya menyampaikan informasi dengan bahasa yang baku dan sulit dimengerti, namun mereka menjadikan informasi tersebut layaknya sebuah cerita. Sehingga para pembaca pun tertarik dan ingin membacanya. Target yang bertumpu pada engagement merupakan juga bentuk strategi untuk meraih kedekatan dan keikutsertaan masyarakat dalam konten yang dibuat.

\section{Ucapan Terima Kasih}

Penulis mengucapkan terima kasih kepada seluruh narasumber dan pihak lainnya yang telah membantu selama proses penelitian ini berlangsung. Ucapan terima kasih juga diberikan kepada Fakultas Ilmu Komunikasi Universitas Tarumanagara yang telah mempublikasikan hasil penelitian ini.

\section{Daftar Pustaka}

A.Muri Yusuf. (2014). Metodologi Penelitian Kuantitatif, Kualitatif \& Penelitian Gabungan. Jakarta: Prenademeia Group

Bungin, Burhan. (2007). Penelitian Kualitatif: Komunikasi, Ekonomi, Kebijakan Publik dan Ilmu Sosial lainnya. Jakarta: Putra Grafika

Bungin, Burhan. (2011). Penelitian Kualitatif. Jakarta: Kencana Prenada Media Group Creswell, J. W. (2010). Research design: pendekatan kualitatif, kuantitatif, dan mixed. Yogyakarta: PT Pustaka Pelajar.

Darmadi, Hamid. (2013). Metode Penelitian Pendidikan dan Sosial. Bandung: Alfabeta.

Dr.Jr.Raco, ME., M.Sc. (2010). Metode Penelitian Kualitatif: Jenis, Karakter, dan Keunggulannya. PT. Gramedia Widiasarana Indonesia, Jakarta.

Effendy, Onong Uchjana. (2016). Ilmu Komunikasi - Teori dan Praktek. PT. Remaja Rosdakarya. Bandung

Gunawan, Imam. (2014). Metode Penelitian Kualitatif: Teori dan Praktik. Jakarta: Bumi Aksara 
Idrus, M. (2009). Metode penelitian Ilmu Sosial. Yogyakarta: PT. Gelora Aksara Pratama

Kennedy, John. Dermawan Soemanagara. (2006). Marketing Communication. PT. Bhuana Ilmu Populer: Jakarta

Kotler, Philip dan Kevin Lane Keller. (2008). Manajemen Pemasaran, Jilid 1. Penerbit Erlangga

Kriyantono, Rachmat. (2006). Teknik Praktis Riset Komunikasi. Jakarta : Kencana Prenada Media Group

Moleong, Lexy J. (2007). Metodologi Penelitian Kualitatif. PT Remaja Rosdakarya Offset, Bandung

Moleong, L.J. (2010). Metodologi Penelitian Kualitatif. Bandung: Remaja Rosdakarya

Moleong, Lexy J. (2012). Metodologi Penelitian Kualitatif. Bandung : PT Remaja Rosdakarya.

Moleong, Lexy J. (2014). Metodologi Penelitian Kualitatif. PT Remaja Rosdakarya, Bandung.

Morissan. (2010). Periklanan: Komunikasi Pemasaran Terpadu. Kencana: Jakarta

Mulyana, Deddy. (2008). Ilmu Komunikasi: Suatu Pengantar. Bandung: Remaja Rosdakarya

Nazir, Moh. (2013). Metode Penelitian. Bogor: Ghalia Indonesia.

Prisgunanto, Ilham. (2006). Komunikasi Pemasaran: Strategi \& Taktik Dilengkapi Analisis SOSTAC dan STOP SIT. Jakarta Ghalia Indonesia. Jakarta

Pudjiastuti, Wahyuni. (2016). Social Marketing: Strategi Jitu Mengatasi Masalah Sosial di Indonesia. Yayasan Pustaka Obor Indonesia. Jakarta

Purnama, Hadi. (2011). Media Sosial di Era Pemasaran 3.0 Corporate and Marketing Communication. Jakarta

Sugiyono. (2007). Metodologi Penelitian Bisnis. PT. Gramedia, Jakarta

Sugiyono, (2008). Metode Penelitian Kuantitatif Kualitatif dan R\&D. Bandung Alfabeta.

Sugiyono. (2010). Metode Penelitian Pendidikan Pendekatan Kuantitatif, kualitatif, dan $R \& D$. Bandung: Alfabeta.

Sugiyono. (2013). Metode Penelitian Pendidikan Pendekatan Kuantitatif, Kualitatif, dan $R \& D$. Bandung: Alfabeta.

Sukmadinata, Nana Syaodih. (2009). Metode Penelitian Pendidikan. Bandung : Remaja Rosdakarya

Suryabrata, Sumadi. (2012). Metodologi Penelitian. Jakarta: Rajagrafindo Persada.

Suryadi, Edi. (2018). Strategi Komunikasi. PT. Remaja Rosdakarya. Bandung

https://journal.untar.ac.id/index.php/komunikasi/article/view/1078/833

http://demo.orangutan.or.id/id/orangutan-faq

https://orangutan.or.id/id/

http://orangutan.or.id/id/fakta-orangutan/

perpustakaan.uns.ac.id

www.emeraldinsight.com/2042-6763.htm 